\title{
Application of Adaptive Structure based on Natural Inspiration on Biomimicry Architecture
}

\author{
Riri Chairiyah ${ }^{1}$, Ahmad Sarwadi ${ }^{2}$, SyamRachma Marcilia ${ }^{2}$ \\ ${ }^{1}$ Postgraduate Department of Architecture and Planning, GadjahMada University, Yogyakarta, Indonesia \\ ${ }^{2}$ Department of Architecture and Planning, GadjahMada University, Yogyakarta, Indonesia
}

Corresponding e-mail: riri.chairiyah@mail.ugm.ac.id

\section{Article info:}

Received : 18-09-2018; Revised : 26-09-2018; Accepted : 27-09-2018

\begin{abstract}
This paper discusses the application of Biomimicry Architecture to the design of adaptive structural designs. Today, with the development of technology and materials, architectural Biomimicry has been widely used in particular to support sustainability building systems because the approach used by biomimicry is to study nature, which nature has a principle to always live in harmony with its environment. Living harmony done by nature is one of them is the ability of natural adaptation. A number of applications of the ability of natural adaptation, by architects have been widely applied to building design, but the application of building design still tends to aesthetic and functional aspects, while architecture also has strength aspects that must be considered by architects. This aspect of strength is manifested in a good and safe building structure design. Based on this problem, this study then used content analysis method with qualitative inductive type. The study was conducted by analyzing written information data that discussed the case of selected buildings, namely The Eden Project Building, The Gherkin Tower and The EastgateCenter. The findings of the study are descriptive explanations related to how the adaptive application applied by architects to the design of the building structure uses natural inspiration. The findings of the study include three types of application, first the application of the principle of adaptive structure that adjusts the conditions / site around the environment is built, the second application of the principle of adaptive structure that adjusts to the weather around the built environment, and the third application of the principle of adaptive structure that adapts to the climate around the built environment. The benefits of this research are expected to provide insight for architects to design buildings that are adaptive to the environment, especially from structural systems and can expand the science of Biomimicry Architecture.
\end{abstract}

Keywords: Biomimicry Architecture, Structure, Adaptive

\section{Introduction}

ArashVahedi (2009) mentions, "The history of architecture begins with getting help and ideas from nature directly, so that with the development of technology this increasingly affects human life". The beginning of the human life settled, humans use caves as a place to live, they use natural elements directly to shelter. As humans develop to learn from nature, humans begin to make a place to live like a bird that makes a nest by gathering branches of leaves. Humans also imitate nature by utilizing environmental material to make a place to live. The simplicity of knowledge in processing and the use of nature which is learned directly from the way nature uses, forms a work of human beings that is in harmony with environmental conditions.

However, along with the development of time, science and human technology, humans not only use nature directly as a place to live, but do engineering on the resources around them. The engineering has shifted so that humans exploit nature such as excessive use of forest wood to build homes without reforestation. The impact of natural exploitation is the lack of available resources to build a place to live and then use substitute materials. Replacement 
materials for building are brought in from outside the built location, which is often not friendly to the built environment. This makes the environment more negative.

Scientists, in particular architects who are aware of this, are starting to make improvements to reduce these adverse effects. A number of development sciences from architecture such as Ecological Architecture, Sustainability Architecture, and Green Architecture are fields of science that address development issues with the environment. Biomimicry architecture has also become one of the ways in which scientific fields are now widely used to overcome development problems with the environment like sustainability architecture. This is because the biomimicry approach that uses Architecture as a model, mentor and measuring tool in designing (Janine Benyus, 2002) has the principle of living harmoniously with the environment he lives in and using the surrounding resources in a non-excessive manner according to the natural function (Janine Benyus, 2007) which is in line with one of the factors of sustainability to do development by reducing the impact of environmental damage due to human possessions today, which can threaten the fulfillment of the needs of future generations.

Nature is the source of architect's inspiration in designing buildings to find solutions so that man-made and natural buildings can be harmonious. Natural elements also have their own uniqueness in the process of adjusting to the environment he is in. The natural adjustment process produces a number of forms, processes and systems of life cycle that are in harmony with the environment he is in. This lesson is used by architects as inspiration in the design of the building. Architects in designing buildings or dwellings, pay attention to a number of important aspects before a design is formed. Vitruvius in his book De Architectura (Book 1, chapter 3), mentions that a good architectural design is paying attention to three aspects of aesthetics (venustas), functions (utilities) and strength (firmity). Which of these three things complement each other. However, today architects use the biomimicry architecture model to prioritize aesthetics and function in designing adaptive buildings, while the strength aspects applied in the building structure system are less noticed. This study specializes in discussing the work of biomimicry architecture related to its application in the aspect of structural strength, which is reflected in its structural system. How architects use natural inspiration gained in the adoption of adaptive building structure design is the main topic of discussion. With this, various adaptive principles can be found in the building of architectural works that can be illustrated in the building structure model, process or system.

\section{Methods}

This research uses content analysis method to find the application of adaptive structure based on natural inspiration found in the Biomimicry Architecture building. Content analysis method in the opinion of Krippendorf (1993), is a research technique that makes the data that has been obtained is formed the conclusion, these data must not be separated from the context. Meanwhile, according to Muhadjir (2000), Content Analysis is the form of extracting the contents of messages from a communication. So it can be concluded that content analysis is the method used by researchers by examining the data, especially written data that is chosen based on the purpose of the research conducted. This study uses inductive qualitative content analysis, in which the theory is obtained directly from written information data that is used with the final result in the form of descriptive explanations.

The study uses three selected cases selected based on specific criteria, namely the case can represent the identity of the Biomimicry Architecture building, the building has been built, the period of the building is clear or calculated, has a lot of written data discussion, and is related to natural adaptability. The results of the case criteria were selected three building cases, namely The Gherkin Tower, The Eden Project, and The EastgateCenter. The three cases were then searched for as much textual information as possible such as journals, 
scientific reports and design reports, which discussed the case and related to the purpose of this study. Textual information can be in the form of an architect / designer statement on his work or researchers, critics, experts who discuss the case of the research.

After finding textual information data, then the content analysis process is carried out, in which the content analysis process generally has five stages (Mario, 2015) namely Unitization, Categorization, Codification, Inference and Verification. Unitization is carried out by sorting out textual information from all three cases related to the principle of adaptive structure. The categorization is done by grouping the results of the data units from the three cases based on the similarity of criteria whose parameters are found from the case unit and the categories formed are given the name / mention namely codification. The codification results were then abstracted descriptively based on the information data patterns found. The results of abstraction are the results of the conclusions of this study. Each stage of the content analysis that is passed, a verification process of the previous stages is carried out, this is to see whether the work done is right and correct.

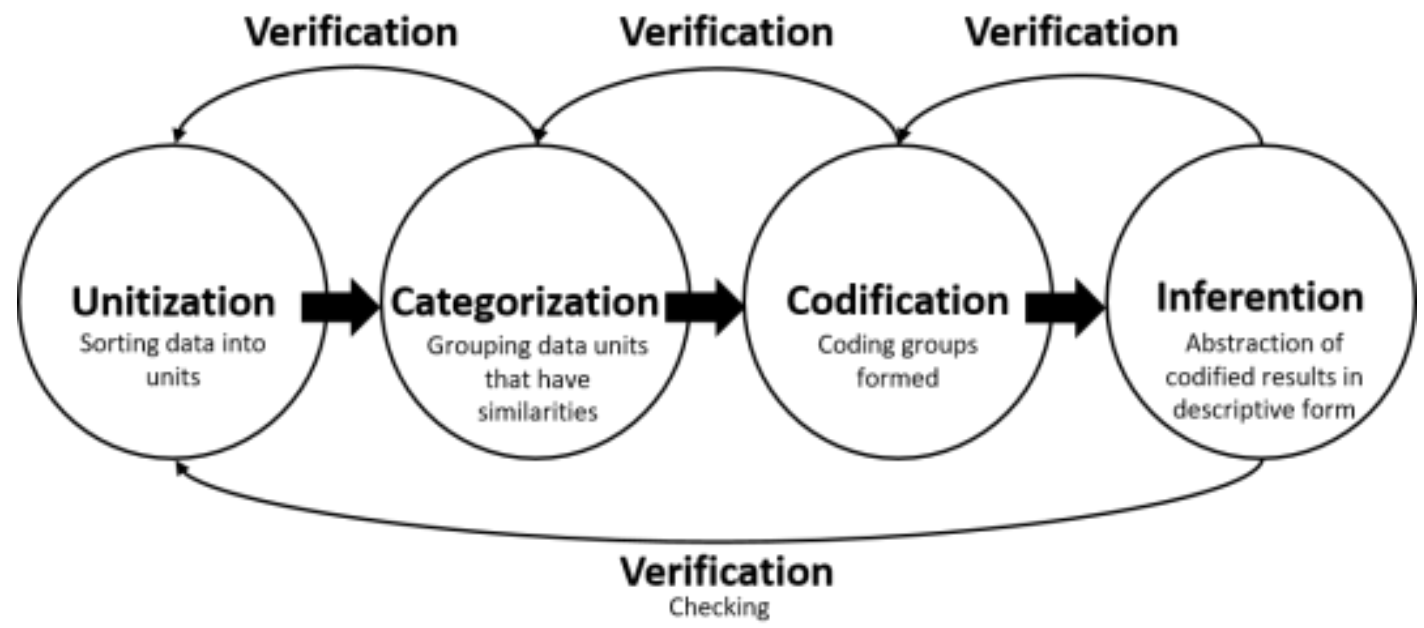

Figure 1. Stages of Content Analysis (Chairiyah, R. 2018)

\section{Discussion}

Content analysis begins with unitization of each selected case used (The Eden Project, The Gherkin Tower, and The EastgateCenter). Unitization is collecting units that can be in the form, words, sentences or paragraphs found from written data. From the results of the unitization stage, the Case of The Eden Project found four units derived from written literature data, The Gherkin Tower Case contained four units, and the case of The EastgateCenter contained three principal thought units which explained the principle of adaptive structure based on natural inspiration.

All units are grouped / categorized based on the similarity of the unit data pattern. From the results of grouping obtained certain themes that display the principle of adaptive structure based on natural inspiration. The last stage that is carried out is inference, the codified results are abstracted. The abstraction is made by constructing patterns found in units that are crystallized and explained in descriptive form used in the work of Architecture Biomimicry. Thus found three types:

- application of adaptive principles carried out by architecture in his work with the basis of natural inspiration namely the environment is built

- Application of the principle of adaptive structure that adapts to the weather around the built environment 
- Application of the principle of adaptive structure that adapts to the climate around the built environment

\subsection{Unitization}

Unitization will be explained based on each selected case, namely:

\subsubsection{The Eden Project Case}

The Eden Project as a building located in Cornwall, England was designed by architects Nicholas Grimshaw and Partners Architects. The background of a number of project challenges is contoured and unstable environmental conditions and the function of the building as a community education center related to the natural world so that a large room is needed that can accommodate various plants in it. The architect team tried to find inspiration from nature to solve the problem. In answering the challenges of the project, namely building buildings on contoured and unstable environmental land, architects used inspiration from soap bubbles. Soap bubbles have the character of being able to adjust their shape where they stick. This inspiration is applied in the design of a building structure with a dome shape like a soap bubble that can be placed anywhere, as mentioned in the quote below.

(E1) "... an easy adaptation to the land on which it was made just like a soap bubble" (Sylwia Cygan, 2012).

(...)

(E2)"...adapts easily to most ground surfaces. Eden's designers describe the domes as giant bubbles that can be set down just about anywhere..." (Tom Haris, 2010).

Inspiration of soap bubbles that can be placed anywhere, affects the shape of the structure used by the building. The shape of the dome structure in the building is adjusted to the shape of the existing site. Besides that, the dome consists of a series of geodesic structural frame pieces that make it easy for buildings erected on contoured clay to adjust changes from the soil such as the developing and shrinking soil conditions. This is explained in the quote below:

(E3) "Adaptable: structural form configured to the shape of the site"(Sa'id Kori, 2013).

(...)

(E4) "In addition, a geodesic dome-like structure would be able to conform to the expanding and contracting contours of the clayey soil." (Sa'id Kori, 2013).

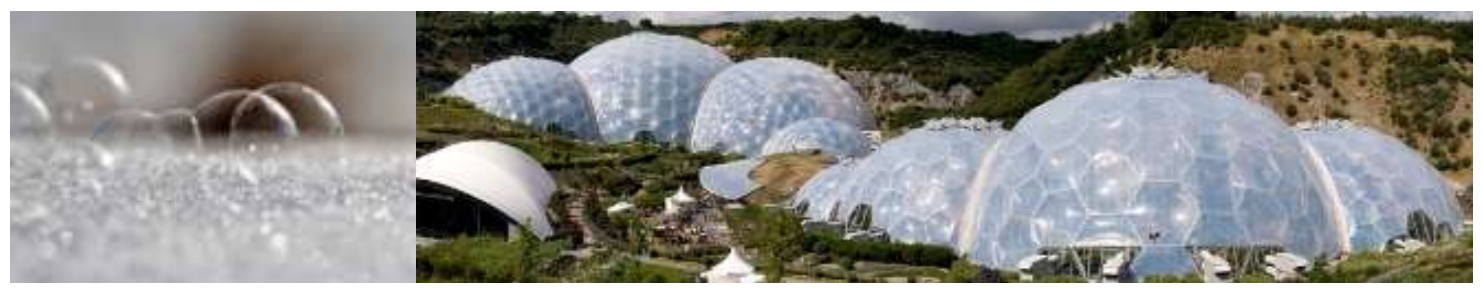

Figure 2. Soap Bubbles and Dome Eden (Chairiyah, R. 2018)

\subsubsection{The Gherkin Tower Case}

The Gherkin Tower is a building located in London, United Kingdom. Against the backdrop of an office building that had to stand on a crowded city land requires the Gherkin building to be a high-rise building. The High-rise building has so far been constrained to be able to deal with the wind where the higher the building, the tighter the wind flow will be faced by the building. The team of architects, Tim Foster and Partners, used natural inspiration in the form of Venus Basket Flower to be an inspiration for Gherkin's building design. The round shape in the Venus Basket Flower is the answer to the challenge of high-rise buildings, in 
overcoming the problem of strong wind currents. Basket Flower Venus that lives at the bottom of the water must face strong water currents, with the cylindrical shape of the Venusian flower, the Venusian body can spread the pressure received so that the Venusian Flower has the ability to survive in its environment. In addition, the fibers in the hexagonal Venusian flower body help Venus Flower to spread the pressure of the water flow it receives. This inspiration by Foster was used as an inspiration for the type of structure used to support cylindrical building shapes, which together served to hold and spread the wind currents faced by buildings. These two things as shown from the source below:

(G1) "Venus flower Basket sponge sits in an underwater environment with strong water currents and its lattice like exoskeleton... help disperse those stresses on the organism. Architect Norman Foster inspired by this Venus flower designed Gherkin tower, which has hexagonal skin." (Rajshekhar Rao, 2014).

(...)

(G2) "...lattice-like exoskeleton helps to disperse stresses on the organism and its shape reduces forces of strong water currents- both of which were applied to Foster's design" (U.S. Green Building Council, 2013)

(...)

(G3) "The Venus Flower Basket in this species, the skeleton comprises an elaborate cylindrical lattice-like structure with hierarchical span levels. This strategy when applied to construction helps building wind-resistant structures..." (Sahil Virmani, 2015)

Inspiration of the shape of the leather fiber lattice that surrounds the Venus Flower, as quoted below, translates into the design of the building structure that covers the entire cylindrical shape of the building. The fiber is translated using steel material as a building structure.

(G4) "The steel structure allows the wind to easily whip around the tower. Its skin and shape are inspired by the lattice-like exoskeleton of the Venus Flower Basket Sponge an organism living in the deep ocean - that helps the sponge to disperse strong water currents."(Mega.online , 2016)

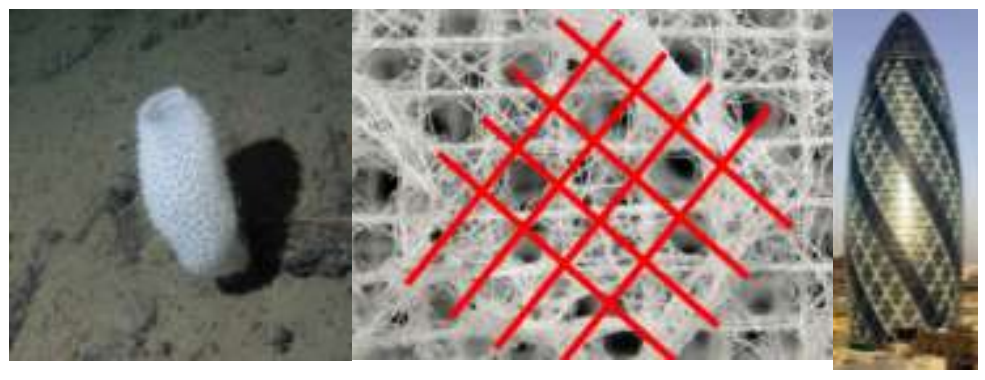

Figure 3. Exoskeleton The Venus Floer Basket and The Gherkin Tower(Chairiyah, R. 2018)

\subsubsection{The Eastgate Centre Case}

The Eastgate Center is a building located in Harare, Zimbabwe, Africa. The architect team holding the project is headed by Mick Pearce in collaboration with Arup Associates. Against the background of the need for buildings as offices and shopping centers, Eastgate was established. However, Eastgate has a challenge that the building is designed not to use AirConditioning while the location of buildings in Africa have high temperature climatic conditions so that the proper design of buildings is needed so that the building remains comfortable. 
Mick Pearce with this condition uses inspiration from termite nests that are found in Africa. Termites that live inside the nest even with extreme climatic conditions can survive. A number of inspirations of Zimbabwean termite nests were applied by Pearce to Eastgate building design and there were several inspirations that influenced Eastgate's building structure design. The inspiration learned from the termite nest is how the termite nest building is designed, especially in this article is a part of the structure that can adapt to its environment. This is formed from the pores of termite nests which are the way the nest can adapt to climatic conditions in its environment. Based on the quote below, the adaptive principle by the architect was applied to the structure of the beam and column arrangement structure, especially on the wall.

(S1) "We could turn the whole idea of the wall on its head," he said in a New Scientist article. "We should not think of walls as barriers to stop the outside getting in, but rather design them as adaptive, porous interfaces that regulate the exchange of heat and air between the inside and outside. Instead of opening a window to let fresh air in, it would be the wall that does it, but carefully filtered and managed the way termite mounds do it." (Phil Fung, etc., 2011)

The above quote also explains how the nest structure that can act regulates internal and external air exchange. Reinforced by the quote below which mentions the structure of termite nests designed to create temperatures in the nest that remain good for termites. This inspiration became the principle of forming the structure of the Eastgate building that the architect tried to implement.

(S2) "structurally The structure inside a termite nest is made in such a way that the temperature inside remains optimum and thus providing ambient living conditions for the termites to thrive upon..." (A.Geetha , 2011)

One of the inspirations that influenced Eastgate's structural design principle was in the design of the floor plate / ceiling structure from the lower floor space to the surface of the plate, material, thickness of the material to the arrangement of the floor plate that forms the ventilation chamber is to support the structural principle thermoregulative or can create optimal temperature conditions in Eastgate buildings. As mentioned in the quote below:

(S3) "Resembling the termite mound, the ceiling in the atrium in the second Municipal O ffi ce Building in Melbourne is made of rough precast sandblasted corrugated concrete, and the ceiling is $180 \mathrm{~mm}$ thick, $8 \mathrm{~m}$ long, and $21 \mathrm{~m}$ wide. The undulating space (ruang bergelombang) can absorb the heat produced by users to an optimal extent, promoting cross ventilation and increasing the natural light received by the space near the wall" (Yanping Yuan, etc., 2017).

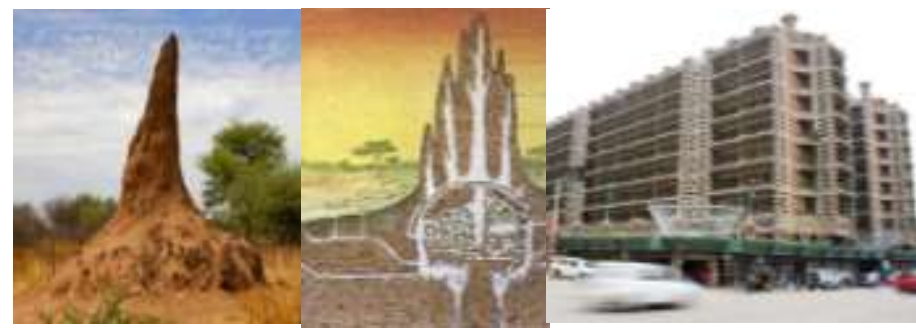

Figure 4. Zimbabwean Termite Nest and The Eastgate Centre (Chairiyah, R. 2018) 


\subsection{Categorization and Codification}

The Application group of adaptive structures found based on data units from each case is grouped based on the pattern of similarity of application to the structural system. Eleven unit data found in the unitization stage related to the adaptive principles used by architects were then combined and differentiated based on the application of natural adaptive inspiration to buildings. The results of the grouping of data units found that there were three groups applying adaptive principles to the architecture structure of Biomimicry. The grouping is reflected in the selected cases that represent different applications based on the natural inspiration used.

The grouping is the first group with the Eden Project Case in four units, the second group with four Gherkin Tower cases, and the third group with three EastgateCenter cases. The three groups are then given codification according to the parameters found from the category. The parameters are environmental conditions that influence the occurrence of adaptation by natural elements that are used and that are applied to buildings. The results of naming these categories are:

- Application of the principle of adaptive structure that adjusts the conditions / site around the built environment

- Application of the principle of adaptive structure that adapts to the weather around the built environment

- Application of the principle of adaptive structure that adapts to the climate around the built environment

The natural ability to adapt to the environment is used by the three architect teams in designing the building. This was motivated by the three cases of the building to be able to adjust to the condition of the building's built environment. The Eden Project building faces contoured and unstable soil environmental conditions, Gherkin buildings face environmental conditions faced by strong wind currents and Eastgate buildings face environmental conditions with extreme climates. Architects study natural elements so that they can be a solution to the problems faced. The solution affects the structural principle of the designed building.

\subsection{Inferention}

The adaptive structure of the Biomimicry Architecture building is the adjustment of the design of the building structure so that it is able to adjust itself, in harmony or harmony with the environment he has built. The adaptive structure of the Architectural building of Biomimicry comes from natural inspiration and is shaped by the architect's need to find solutions in order to solve the environmental problems faced when designing. These environmental problems in their application can be grouped into three, as for the abstraction as follows:

a. The application of adaptive principles based on natural inspiration that adjusts the contour / site around the built environment,

Eden Project uses natural element inspiration in the form of bubbles that have adaptive properties, in which the bubble surface can adjust to the environment he is in. The application of the designer in the building by making a form of structure that has similar principles so that the building can adapt to its environment, namely the shape of the dome. The application of the dome shape inspired by soap bubbles, makes the building easy to adjust to the contour / soil environment. 
b. Application of adaptive principles based on natural inspiration that adjusts to the weather around the built environment,

Gherkin Tower in answering the environmental problems faced using the inspiration of the Venus Basket Flower that lives in water, with its cylindrical shape having a lattice makes the Venusian Flower live in an environment with strong water currents. The shape of the cylinder and the shape of the lattice of the Venusian Flower can reduce water pressure through its shape. This is applied to the aerodynamic structure of the building which allows the wind to be divided by circling the building. The Gherkin Tower building uses the application of a cylindrical shape and the shape of the lattice of the Venus Flower which is applied to Gherkin building shapes and selection of types of structures such as nets.

c. The application of adaptive principles based on natural inspiration that adjusts climatic conditions around the environment is built in the Eastgate Center case.

The Eastgate Center case against a backdrop of extreme climate using termite nest inspiration. Adaptive inspired by termite nests are used in structures to create a comfortable nest condition for living in an environment with hot weather. Termite nests do not close the walls to isolate from the environment, but are designed so that they have the ability to connect the natural environment and the building environment in order to store thermal and release thermal. Termite structure systems that are thermoregulative or have the ability to regulate temperature are also applied to Eastgate buildings. One of the capabilities applied to the building structure is the ability to maintain the temperature in the building by absorbing heat. The principle of thermoregulation affects the design of building structures, such as the selection of materials that have the ability to store heat and form structures that adjust the function of the airways.

\section{Conclusion}

Nature has a variety of ways to be a source of inspiration for humans. One of them provides new innovations for the development of building technology, especially in the design of architectural structures. Nature also has a number of peculiarities in the face of the environment she lives to survive or adapt. This is manifested in natural forms, behavior and systems. The uniqueness of nature, in the world of architecture, one of which is used to find solutions to environmentally friendly development problems. Environmentally friendly development can be realized in the formation of aesthetics, functions and strengths. Strengths derived from the design of building structures, become one of the important points to be considered. Without good strength, the building will not function properly and aesthetic value will be in vain because of the lack of value in building safety. The design of building structures also requires new solutions to increase the strength of the building structure. The selection of natural elements that are appropriate to the problem can help architects to find new application solutions to the type, shape of structure, and type, shape of building materials. Besides that, adaptive natural inspiration creates a structure that not only has strength, but is environmentally friendly.

This study aims to find the application of adaptive structures based on natural inspiration, which has been used by architecture in architectural building works with a biomimicry approach. Of the three selected cases, there were three types of adaptive natural inspiration applied to building structure design, namely natural inspirational building-based adaptive application that adjusts contour / site around the built environment, natural inspiration-based building adaptive application that adapts to the weather around the built environment, and adaptive application natural inspiration-based buildings that adjust the climatic conditions 
around the built environment. Of the three types of application in the implementation of the building structure of biomimicry architecture can be a flexible form selection such as the shape of a curve that can adjust to the contour of the environment, selection of cylindrical or vertical curves that are aerodynamic so that it has the ability to spread pressure, supported by a structure such as a network structure. Finally, the form of implementation can be in the form of selecting structural materials that are suitable for the climatic conditions of the building environment such as the use of materials that have a high lag time.

\section{References}

Mega. (2016). Sustainable Architecture; Taking a Leaf Out of Nature's Book.Reading, Mass.: mega.

Fung, P., Axworthy, N. (2011). Mimicking Nature. Reading, Mass.: Engineering Dimensions.

Lionar,M. (2015). Konsepsi Arsitektur Balkrishna Doshi: Kajian Paradigma Balkhrisna Doshi mengenai Arsitektur India. Thesis, Department of Architecture, Gadjah Mada University

Cygan, S. (2012). Eden Project - Identification of The Revitalisation Undertaking Success Factors. AGH Journal of Mining Geoengineering, 36(2), 101-109.

Rao, R. (2014). Biomimicry in Architecture. International Journal of Advanced Research in Civil, Structural, Environmental and Infrastructure Engineering and Developing, 1(3), 101-107. ISSN_NO: 2320-723X. 2014.04.08.

Geetha A. (2011). Master Architect of The Creature World Final. International Journal of Computer \& Organization Trends, 1(1), 1-4. ISSN: 2249-2593. May 2011.

USGBC. (2013). Biomimicry + Architecture Life's Principles. U.S.: Urban Green Council EP Monthly Forum.

Yuan, Y., Yu, X., Yang, X., Xiang B., Wang. (2017). Bionic Building Energy Efficiency and Bionic Green Architecture : a Review

Haris, Tom. (2010). How The Eden Project Works. (science.howstuffworks.com) 